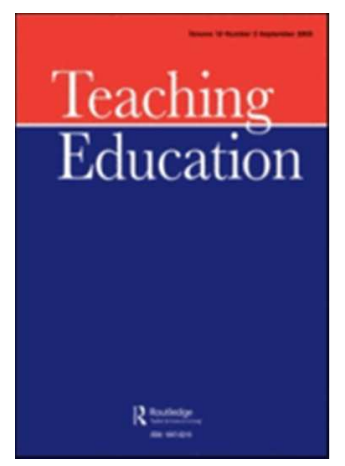

\title{
Assessment for Learning and Teacher Learning Communities: UK teachers' experiences
}

\begin{tabular}{|r|l|}
\hline Journal: & Teaching Education \\
\hline Manuscript ID: & CTED-2012-0025.R2 \\
\hline Manuscript Type: & Research \& Scholarship \\
\hline Keywords: & teacher thinking and knowledge, teacher education curriculum \\
\hline & \\
\hline
\end{tabular}

SCHOLARONE ${ }^{\text {Ix }}$

Manuscripts 


\begin{tabular}{|l|l|l|}
\hline INTERVIEW DATE and FORM & INTERVIEW PARTICIPANT & FACE TO FACE OR BY PHONE \\
\hline INDIVIDUAL, APRIL 2010 & Lead Teacher, Hillside School & Phone \\
\hline INDIVIDUAL, MAY 2010 & $\begin{array}{l}\text { Lead Teacher, Pleasant Row } \\
\text { School }\end{array}$ & Face to face in school \\
\hline INDIVIDUAL, MAY 2010 & $\begin{array}{l}\text { Lead Teacher, Southview } \\
\text { School }\end{array}$ & Phone \\
\hline INDIVIDUAL, MAY 2010 & Lead Teacher, Westend School & Face to face in school \\
\hline GROUP INTERVIEW, MAY 2010 & $\begin{array}{l}\text { Group of teachers participating } \\
\text { in school's TLCs, Hillside School }\end{array}$ & Face to face in school \\
\hline GROUP INTERVIEW, MAY 2010 & $\begin{array}{l}\text { Group of teachers participating } \\
\text { in school's TLCs, Pleasant Row } \\
\text { School }\end{array}$ & Face to face in school \\
\hline GROUP INTERVIEW, MAY 2010 & $\begin{array}{l}\text { Group of teachers participating } \\
\text { in school's TLCs, Southview } \\
\text { School }\end{array}$ & Face to face in school \\
\hline GROUP INTERVIEW, MAY 2010 & $\begin{array}{l}\text { Group of teachers participating } \\
\text { in school's TLCs, Westend } \\
\text { School }\end{array}$ & Face to face in school \\
\hline $\begin{array}{l}\text { GROUP INTERVIEW, MARCH } \\
\text { 2010 }\end{array}$ & $\begin{array}{l}\text { supporting the project [CA and } \\
\text { CM cited in text] }\end{array}$ & Face to face at the University \\
\hline
\end{tabular}

Table 1. To show interview arrangements and participants 
Assessment for Learning and Teacher Learning Communities: UK teachers' experiences

\begin{abstract}
In this paper I explore the experiences of secondary teachers in four London schools [UK]

who participated in Teacher Learning Communities, defined as meetings in which

professional learning was supported as they learned about Assessment for Learning. The

claim for these communities is that they lead to sustained improvements in teaching and

learning, where the following design principles are adhered to: where leaders respect and

value a need that has been identified by participants as of importance to themselves; they
\end{abstract}

are school-based and integral to school operations; there is teacher collaboration; and there

is input from within and beyond the school to support teachers' theoretical as well as

practical learning. The findings from this research project suggest that Teacher Learning

Communities' benefits were compromised specifically: where they were imposed on

teachers; where they were not accommodated sufficiently within other school

commitments; where leaders were too directive; where meeting formats were adhered to

inflexibly; and where practice was emphasised at the expense of theories. My conclusion is

that both Assessment for Learning and Teacher Learning Communities rely for their success

on sustained critical reflection among their participants which can be inhibited where the

above limitations apply.

\title{
Introduction: Teacher Learning Communities as Continuing Professional Development (CPD)
}

The claim for Teacher Learning Communities is that their uptake can support student progress. It is suggested that this comes about because teachers who have entered learning communities tend to develop greater confidence, an enhanced belief in their power to

URL: http://mc.manuscriptcentral.com/cted Email: tej@qut.edu.au 
make a difference to pupil learning, enthusiasm for collaborative working and a greater commitment to changing practice and trying things out (Earley and Porritt, 2010; Stoll et al, 2006). Through a group of teachers' continuous learning in a community, it is claimed that teachers can mutually enhance each other's and their pupils' learning, thus building capacity for sustainable improvement.

The Teacher Learning Communities described in this paper are learning communities formed of some or all teachers in a school, who meet regularly to reflect on their own and each other's Assessment for Learning (AfL) practice in order to develop as teachers. The Teacher Learning Communities are distinct from Professional Learning Communities in that their focus is specifically on practice, in this case AfL practice, rather than teaching and learning more generally (Thompson and Wiliam, 2008). Recent reviews of teachers' CPD suggest that Teacher Learning Communities embody characteristics closely associated with sustained improvements in schools' teaching and learning (Earley and Porritt, 2010; Hawley and Valli, 1999; Hustler and et al, 2003; Leahy and Wiliam, 2012 forthcoming; McKenzie and Santiago, 2005; Schwille and Dembele, 2007; Stoll et al, 2006; Villegas, 2003). This article seeks to explore, through data from teacher interviews, how participants experience the actual functioning of these Communities in terms of those features most closely associated with successful CPD. Evidence is sought from interview data collected in four London schools, UK. The lead teacher for Communities was interviewed individually in each school, and a group of participating teachers was subsequently interviewed in each school.

Meetings were observed, and supporting consultants interviewed too. 


\section{Teacher Learning Communities in London schools: design principles}

In July 2007, the [] made available funds for the establishment of Teacher Learning Communities to develop AfL in mathematics, science, and modern foreign languages in the secondary schools of one London borough, UK. In July 2008, a series of three training events on the use of these Communities was run by the [] -one for each school subjectfor teachers in the participating schools. Representatives from all nine secondary schools in the borough attended. Dylan Wiliam, known for his enthusiasm both for AfL and for Teacher Learning Communities, made these initial presentations himself, although his subsequent involvement in the project was at the managerial level.

Participants from six of the nine schools made firm plans for the implementation of Teacher Learning Communities. Four of these volunteered to be part of the research reported in this paper, named here as follows: Hillside School; Pleasant Row School; Southview School; and Westend School. These schools were encouraged to base their Communities on the format established by Wiliam (2008), although, as this paper seeks to illustrate, different schools interpreted the format in particular ways (The original model is also described in detail in Leahy and Wiliam, 2012, forthcoming). Wiliam suggested monthly meetings but practice in the London project was more varied with six-week intervals between meetings being common. In the original model, 75 minutes was suggested as a minimum time for meetings and that 8 to 12 participants was the optimum number. In the London Communities, meetings were sometimes shorter than 75 minutes although never longer, and participants could be as few as five teachers [Hillside School] or as many as 13 [Southview School]. Such practical differences from the design principles of the model may account for the range of 
experiences described by the teachers who attended them. The Communities in the London project used to greater or lesser degrees the following agenda suggested by Wiliam (2008).

Introduction (5 minutes)

Agendas for the meeting are circulated and learning intentions presented.

Starter activity (5 minutes)

Participants engage is an activity to help them focus on their own learning.

Feedback (25 minutes)

Each teacher gives a brief report on an AfL practice they last time committed to try out, while the rest of the group listen appreciatively and offer support.

New learning about formative assessment (20 minutes)

Each meeting includes an activity that introduces some new ideas about AfL, e.g. a task, a video, or book study.

Personal action planning (15 minutes)

The participants plan in detail what they hope to accomplish before the next meeting. This may include trying out new AfL ideas or consolidating techniques. They plan peer observations.

Summary of learning (5 minutes)

The group discusses whether they have achieved the learning intentions.

The instigators also developed a CD-ROM called Embedding Formative Assessment which contained materials for running nine monthly meetings. The materials for supporting the meetings ran to 75 pages in total, including agendas, videos, handouts, and notes for the 
group leader. These materials were used directly by the London project although the agendas were more commonly used than other aspects of the package.

\section{Current educational policy in England, UK, and directives about AfL}

It adds insight into the data presented here, to explain that in England, in the 21st Century, an increased de-professionalization of teachers accompanied a policy stance that teaching was a craft rather than a profession (Beck, 2008). This potentially reduced teachers' sense that they act autonomously and drawing on a specialized knowledge-base. Teachers' autonomy to make decisions about curriculum had already been severely limited since the Education Reform Act of 1988 which introduced a prescribed National Curriculum. The Act also enforced national assessments on all children, and later led to prescriptions about how subject matter should be taught. The Act ushered in a radical change to government policy which had previously been explicit about leaving decisions about classroom processes to teachers (Alexander, 2010).

The new national assessments focused teachers' attention on subject matter which would be tested, reinforced by demanding government targets that encouraged extra-curricular cramming in the core subjects of numeracy and literacy. National "league tables" of schools" results, plus increasingly stringent school inspections (OFSTED), added pressure on schools to do what they were required by government rather than as previously, strategies they negotiated with local education authorities. Practices based on AfL were introduced by government to schools, but typically their emphasis in $\mathrm{AfL}$ was on performance rather than on learning. OFSTED inspectors expected children to know what 'level' they were working at, and how they could proceed to the next one. These developments led to a school culture of fear (Jackson, 2010), whereby many teachers were afraid to take initiatives in terms of 
curriculum or pedagogy. Didactic teaching of prescribed content to pupils, working individually or even competitively, was encouraged; and children's cognitive rather than social achievements were emphasized (Alexander, 2010). It was against this backdrop that the research described in this paper was carried out.

The purpose of the Teacher Learning Communities evaluated in this research was to promote one specific aspect of teachers' development, their expertise in AfL. AfL embodies the idea that assessment can be used not only to measure students' attainment, but also to inquire into and enhance their learning at classroom level. However, as pointed out by Hargreaves (2005) and Stobart (2008), adherents to AfL come from diverse perspectives. 'Formative assessment' was already promoted in 1988 in England when the Education Reform Act counted it as one important assessment purpose. Paul Black (1994) defined it at that time as follows:

... frequent assessment carried out to produce feedback so that the progress of individual pupils and the usefulness of the teaching can be monitored and adjustments made (p.191).

This definition hints at the dichotomy within current global perspectives on AfL: the relative roles of teacher and student in the AfL processes. The leftist government in England who left power in May 2010 used a model of assessment to underpin their AfL programme for schools which emphasised teacher direction over students in order to drive students towards prescribed targets (DCSF, 2008). However, some academic writers view this conception as a distortion of AfL, which they claim was developed by Black and Wiliam, both from London, for a national group of academics called the Assessment Reform Group (1998): their emphasis was students' participation in their own assessment and learning as 
well as teachers using data to enhance teaching. Torrance and Pryor (1998) of Sussex University, England, reflected another stance in which the pupils' reflection on their own learning was paramount. Authors associated with the latter body of thinkers claim that pupils' learning autonomy is the ultimate purpose for $A f L$, and that $A f L$ gives explicit roles to learners, as well as to teachers, for instigating teaching and learning (Pedder, James and McBeath, 2005, p.216). Ecclestone (2010) and Pryor and Crossouard (2008) additionally emphasise that critique is an aspect of autonomy that should be achieved through AfL:

The pedagogic texts and the teaching context therefore become the object of critique, rather than functioning to 'deliver' knowledge (Pryor and Crossourd, 2008, p.7).

The emphasis illuminated here closely resembles Leftein's (2005) model for teacher development in which teachers are urged to consider and critique teaching methods drawing on learners' responses, rather than to implement them without reflection. The Teacher Learning Community form of CPD expects teachers to meet together regularly to reflect on their own, and other teachers', expertise in AfL, negotiating the principles underpinning AfL techniques, not just the techniques, so as to be powerful in critiquing which techniques to use, when to use them and why.

However, some well-known techniques have become associated with AfL and indeed their practice is sometimes used to define AfL itself. These include 'traffic lights' whereby students self-assess their greater or lesser grasp of a topic using red, amber and green indicators; 'no hands up' whereby all pupils talk to each other about diverse answers to a question; and the sharing or negotiating of learning intentions and assessment criteria between teachers and students (Hargreaves, 2005). However, teachers' habitual use of 
such techniques has been criticised as fulfilling only the letter rather than the spirit of AfL (Marshall and Drummond, 2006), since teachers' constant reflection with their students, on those aspects of teaching which best enhance learning, is missing from a habitual implementation of such methods. Currently, an uncomfortable mix of AfL models exists in English schools, with those associated with approval from OFSTED perhaps gaining more popularity than those emphasising critical reflection and student initiation.

\section{Research design}

This research was informed by the principles of constructivism, which entails grappling with diverse social constructs, meanings and understandings. Given the small sample of teachers, I could not expect to generalize findings, but I could hope to provoke thought among other teachers and those who support them. At the very least, this study might provide what Bassey (2001, p.5) calls '... a powerful and user-friendly summary which can serve as a guide to professional action'.

I used one main research method, the interview, since the interest was in the experiences of diverse individuals. Observations were used to back up interviews. I aimed to notice patterns across the responses of interviewees, but also valued their idiosyncrasies. Interviews were conducted as part of an evaluation by the [] for the project's funders. In email correspondence before the interviews I explained to participants the topic I wanted to talk about and why, that I would be recording the interview so that it could be transcribed later but that each person would only be referred to by a code in subsequent writing. If this was acceptable to them I invited them to respond to the email as a consent form to sign up before the interview started. They also had the chance to opt out if they changed their mind. Teachers seemed happy for interviews to be recorded but I did find that they did not 
want actual meetings to be video recorded, so audio recordings were made of these as background data. All interview data were transcribed before analysis.

Interviews were mainly conducted face to face in the schools, although two were carried out over the telephone. Four lead teachers in the respective schools were individually interviewed, and there were group interviews of teachers in each of the four schools. The sample was drawn up according to which schools volunteered first. Table 1 presents the interview arrangements.

Table 1.

The supporting consultants to the project were also interviewed (cited here as CM and CA). Interviewees were probed about participant agency, school support, collaboration and subject input, as starting points. Starting point questions were broadly similar for each teacher but could be adapted if appropriate. I took a deductive approach to data analysis. I read through the first six interview transcripts, noting down factors that teachers said were important aspects of their experience. From this initial reading, I developed a framework within which to analyse the rest of the interview transcripts. All transcripts were read multiple times until no new themes presented themselves. I was then in a position to restructure the analytic framework by collapsing some categories and expanding others.

\section{Existing arguments for aspects of Continuing Professional Development}

Recent reviews of CPD indicate that the most useful CPD is provided when leaders respect and value each participant's needs, as identified by the participants as of importance to themselves as individual professionals. 'One size fits all' standardized CPD provision is unlikely to be useful because it does not take account of teachers' existing knowledge, experience, needs and capacity to learn and take decisions (Hustler et al, 2003). Teachers' 
commitment to CPD is heightened where they autonomously initiate change and then receive support in planning and implementing their changes (Lom and Sullenger, 2011; Mushayikwa and Lubben, 2009; Pedder, James and McBeath, 2005). While the organisation of Teacher Learning Communities can allow greater or lesser participant choice and decision making power, by definition, Teacher Learning Communities focus on strategies identified by teachers themselves as useful for their own classrooms. This article investigates participants' experiences of having their own needs respected and valued in the Teacher Learning Communities they attended and any effects they perceived.

These Communities are school based and integral to school operations which is another characteristic of successful CPD, rather than being held in 'one-off' sessions. They depend on teachers having frequent opportunities to witness the effects that their own learning efforts are having on their own students' learning (Baker and Smith, 1999; Schechter, 2010). CPD through Teacher Learning Communities is designed to be continuous and ongoing, involving follow-up and support for further learning. These features are associated with successful CPD, but the research reported here interrogates teachers' own experiences of the ongoing nature of the Communities they participated in and how this helped or hindered their learning. It asks what participants' experience was of school provision in terms of physical and temporal space for Communities.

Collaboration appears to be a key feature of the most useful CPD (Cassidy et al, 2008) and is central to the structure of Teacher Learning Communities. Observing peers teaching is considered a core practice, because it supports the de-privatisation of practice, fosters accountability among participants and focuses directly on classroom teaching and learning. Productive collaboration, however, necessitates that participants have shared values and 
vision, assume collective responsibility, use reflection and inquiry for individual and group development, are inclusive of all possible participants and treat all with equal respect (Stoll et al, 2006, p.226). This implies an egalitarianism in which ascribed status is irrelevant (Little, 1992). In this article, I explore how participant teachers experienced collaboration in their Teacher Learning Communities, the extent to which they felt that these were in fact egalitarian and the ways in which their experiences affected their learning and teaching. Input of information is a vital part of useful CPD and looking beyond the school for sources of learning and ideas is an important ingredient, because CPD needs to be part of a comprehensive change process. Hawley and Valli (1999) argue that successful CPD provides opportunities for teachers to engage in developing a theoretical understanding of the knowledge and skills to be learned, and is not just a matter of 'best practice' being disseminated. Lefstein highlights this approach to CPD, as follows:

Professional development activities could emphasise curricular adaptation and deliberation rather than demonstration and imitation of so-called 'best practices'... Such activities would aim to develop a teaching subjectivity that questions the potential advantages and disadvantages of different methods instead of asking, 'how is that done?' (Lefstein, 2005, p.350).

Teacher Learning Communities can provide these opportunities, sometimes in small portions delivered in sessions with the support of imported printed materials. The teachers whose interview data is used here commented on how central the incorporation of external input appeared to them.

This aim of this paper in short, is to consider the features of CPD most closely related to productivity, as reported by the research literature; to explore teachers' experiences of each 
feature in terms of the actual Teacher Learning Communities they attended; and to throw light on implications their experiences hold for others' practice in the future.

Teachers' experiences of Teacher Learning Communities in relation to features associated with productive CPD

When leaders respect and value a need that has been identified by the participants as of importance to themselves as individual professionals

In one of the four schools, Southview School, the Teacher Learning Community lead teacher described how 13 teachers in her school had recently and voluntarily signed up to regular meetings. She had supported the establishment of a voluntary Teacher Learning Community for mathematics the previous year, and based on its success, she was now establishing a second, cross-curricular one. She put the meetings on the school calendar, and left it to teachers to decide whether to attend or not. She explained that people only attended if they knew they could talk about what they loved doing, teaching, and how they could do it better. She also described '... trying to nurture a workforce that's actually pretty exhausted'. For this reason, participants had to see benefits they personally might gain from attending. In this Community, then, participants identified attendance as of importance to themselves, even if their reasons for attending did not accord with the lead teacher's. The lead teacher had noticed that students were performing less well at A Level than at lower levels, because of the increased learning autonomy expected of students at A Level. She believed that students' autonomy would improve if teachers used AfL practices lower down the school, and this belief drove her own enthusiasm for this form of teacher learning but also encouraged her in leaving her teachers to make their own choices. 
There were those in the schools where Teacher Learning Communities were compulsory who initially saw them as another initiative imposed on them by government and were therefore unwilling to attend. But a selection of these then made the Communities useful to themselves, for example, by adapting Wiliam's agendas so that they better addressed their own particular needs [Westend School]. This way, participants continued to exercise their own agency by making local adaptations. The lead teacher in Westend School claimed that she would never stop a participant from sharing an important experience, simply because the agenda suggested a limited time for talking. In practice, she might have had to draw a meeting to a close at a specified time, but her desire is clear to allow participants some freedom. She said that in her school, teachers were never forced to carry out any particular AfL practices through attending meetings. She said:

They haven't been told that they have to use mini-whiteboards or they have to use lollipop sticks or things. They've got a range of strategies - techniques, rather - that they can use. Some of the staff would love us to say "No hands-up is the policy of the whole school.

In Southview School where attendance was voluntary, adaptations were widely made. For example, the mathematics Community which had run very efficiently for the first year planned to develop in future their own materials to fit into the original agenda formats, but this time with new focuses:

... maybe with the focuses that we think are most important at the time. Yeah. There will maybe be about four or five people who are confident enough to then start up their own teaching and learning group, and then each group may focus on different aspects. 
The lead teachers of Westend and Southview School suggested that the choice and agency of teachers were respected as originally designed, and that this led to enthusiastic participation. This was not, however, the experience of all teachers, even in these two schools. In Westend School, despite the lead teacher's espousal of choice, attendance at meetings was compulsory so that teachers who missed a session had to make up the loss by doing a different activity. Some teachers in that school were sorry to lose the staff meetings that had preceded Teacher Learning Communities. As one teacher there put it, 'I'd like to be left to my own devices a bit more, given a bit more freedom'.

Other teachers argued that if Teacher Learning Communities were to flourish in the future, perhaps some gentle pressure at the start was helpful. For example, one teacher in Pleasant Row School liked being 'forced to reflect on this particular thing'. Similarly, a meeting observed in Hillside School followed the prescribed agenda to the last detail with great relief; but perhaps only because for this activity they did not have to think too deeply. In terms of 'rolling out' the project [Hillside School], again the prescribed agenda and materials made life easier for the teacher responsible. This approach suggests a somewhat minimalist commitment to the Community, which was seen as a necessary but burdensome extra which did not meet local need.

Some teachers seemed to experience the model even more negatively as a one size fits all approach. In some meetings the agenda were followed without much adaptation, and teachers could feel constrained by this. One teacher from Pleasant Row School explained, It was a bit like "Oh, well, we're having a really interesting conversation, but we need to jump to the next thing in order to get everything done." I suppose maybe we felt 
it could have been a bit looser. We wanted a few more questions, didn't we?

Questions posed that we could then discuss rather than lots and lots of set activities.

This perception that each meeting was prescribed in detail may have been encouraged by the Senior Management Team (SMT) who adapted the original model for their own reasons. In this case, the project became associated with school initiatives whose purposes were not those of individual teachers. A teacher in Hillside School expressed the association between Teacher Learning Communities, AfL and OFSTED requirements in teachers' minds:

With the new OFSTED framework this year, there's such an emphasis on AfL that teachers have been working really hard to make sure that they're raising their game to be achieving at least good, if not outstanding lessons. So I think they've seen the importance of the Teacher Learning Communities to help them with that.

CPD associated with meeting school or national rather than personal needs seemed less useful to the teachers, especially because the national CPD agenda had been focussing continually on nationally assessed initiatives, encouraging teachers to dissociate themselves from taking responsibility for their own CPD (Hustler et al, 2003). A teacher in Westend School explained how CPD to meet inspection purposes tended to 'fizzle out':

It fizzles out when people think that we're meant to be like performing seals. Someone comes in to watch us do that exercise, and it's not meant to be that. It's meant to just become part of your teaching.

In such cases, it seemed that teachers were worrying about their performance more than reflecting critically on their own learning and practice. This was a mode that they might default to, but one that did not promise useful learning. The conclusion that can be drawn 
is that choice was highly valued and enhanced teachers' learning, while compulsion by SMT was often resented and could inhibit participation.

What is also fascinating about teachers' comments on this aspect of Teacher Learning Communities is their reflection of the diverse assumptions about autonomy that underpin the practice of AfL in schools. Encouraging autonomy and responsibility and avoiding one size fits all models are issues reflected in the diversity of approach to AfL itself. While for some, AfL is about encouraging student autonomy in learning, for others it is about performing certain actions in order to meet imposed prescriptions. The answer to these dilemmas perhaps lies in asking which learning models are valued: learning as a dynamic, critical process provoking the sometimes uncomfortable construction and reconstruction of conceptions; or learning as covering a prescribed curriculum which is believed to contain all the necessary ingredients.

\section{CPD is school based and integral to school operations rather than being run in 'one-off' sessions}

Five in service training (INSET) days had been introduced by government in England as compulsory for all teachers. However, claims are made that useful CPD is associated with ongoing, gradual teacher development rather than a series of 'one-offs'. A teacher in Westend School described how they were now 'playing around' with the five INSET days by dividing these days up into shorter but more frequent after-school Teacher Learning Community sessions. One teacher in Westend School told me that as a result, Community meetings were the most useful form of CPD she had experienced:

I think, me, this is the one proper ongoing discussion of teaching and learning that I've ever taken part in at this school. There's been the odd session I randomly had at 
INSET, but to actually have sessions that are focused around teaching and learning I think is very positive.

The ongoing nature of Teacher Learning Communities meant that teachers recognized how improving teaching and learning was an ongoing pursuit, never completed, as one teacher at Hillside School explained. Another teacher described the importance of linking one

\section{session to the next:}

Talking about things with other colleagues, actually saying “Okay, I'm going to go away and try this" and then having to come back and say whether you did or didn't, there's been that... I suppose it's kept things going more. There's been a bit more continuity [Southview School].

Some participants acknowledged that the school's SMT needed to show respect for the ongoing Teacher Learning Community process by attending the meetings themselves, giving leaders extra time or mentoring and especially, providing for the practicalities of teachers observing each others' lessons [Southview School; Westend School]. One lead teacher [Southview School], recognizing that teachers were tired and extremely busy with a range of other initiatives, suggested not necessarily making the meetings fixed, calling them off completely at busy times such as examination times, aligning the Teacher Learning Communities explicitly to other school initiatives. In these claims, she reinforced the view that CPD works best when it is ongoing but also when it is built into the school's routines. A different way SMTs tried to make Teacher Learning Communities integral to school business was to make them compulsory for everyone [Hillside School; Pleasant Row School; Westend School]. This, it was believed, would lead to consistency across departments to support the same goal of embedding AfL: 
If we're all doing $[\mathrm{AfL}]$, because we're all doing it as a school there's a certain pressure to be doing it. And because the kids are doing it in lots of lessons, they're not finding it unusual [Pleasant Row].

This solution to integrating Communities into school life seemed to run the risk of limiting teachers' agency in identifying their own CPD needs. Perhaps there was a risk of confusing standardized action with collaborative action. Pressure is rarely the incentive for creative learning (Ryan and Deci, 2000) and again, even if all teachers are implementing the same AfL techniques in their classrooms, this does not in itself mean that it will be equally helpful in all classrooms. Different students will respond in a range of ways to different teachers and experience AfL techniques variously. These are the issues that can be discussed with students, whose learning responses to $A f L$ activities are the criterion by which to judge their success. These are also the issues that can be discussed in the Teacher Learning Communities, once teachers see the incentive to participate in them in the first place.

\section{Teachers collaborate}

Teachers described positively the central role of collaboration in their Teacher Learning Communities. In each of the four London schools, teachers described to a greater or lesser extent, a helpful culture of trust and ambiance within the Community, through which teachers looked out for each other. Once a fruitful culture was established, reflection and inquiry seemed more likely to flourish. The lead teacher in Southview School said:

There's a really good cross-personalisation of skill and knowledge in a humorous, easy environment. I do hear them, the teachers, having conversations about stuff to do with the Teacher Learning Community when it's nothing to do with the meeting. 
One teacher from this environment explained that she helped herself and others to reflect on practice by taking the role of 'challenger' during the meeting, probing critically the comments made by other members of the group about their practice. The energy and positivity of the leader probably contributed to this culture of trust and ambiance [CA]. In another meeting observed, the group consisted of five teachers who were already good friends and colleagues who thoroughly enjoyed visiting each other's classrooms to help themselves and each other improve their practice [Hillside School].

Listening to other people's experiences was seen as inspirational [Pleasant Row School] and the focus directly on learning both important and surprisingly rare [Southview School]. One teacher at Pleasant Row School expressed an explicitly critical approach to practice, inspired by collaborative talk during the Community meetings:

I thought what was really good was the opportunity to discuss some of the routines you've got in your lesson or the routines you've slipped into. To question yourself and ask "Actually, why am I doing that?"

The related question of who was included in the Community was raised many times. There were those who believed that the goal of critical dialogue to provoke a change in one's approach was best achieved by including teachers of a diversity of subjects in each Community [Southview School; CA; Hillside School]. CA felt this applied more to primary than secondary schools:

At primary schools it is absolutely fantastic to have cross-curricular or cross-phases, because it allows teachers to see practice - good practice, and sometimes poor practice, but that's what it's about - in different contexts. 
However, a teacher at Westend School felt that collegial observations needed to be done with someone who taught the same subject as she did, because they could focus better on the detail of AfL within the subject taught.

The non-hierarchical nature of the Teacher Learning Community was seen by some teachers as facilitating fluent, collaborative dialogue. The lead teacher in Southview School felt strongly:

We demand that everyone can get to speak as a teacher, not as some person who holds a stack of responsibility for everything. So yeah, and the great thing about that is the innovation, the energy, the dynamism that you can get through from people who have recently qualified.

In other words, the SMT had no more valuable a voice in the Community than newly qualified teachers: even the pupils had a voice in this Teacher Learning Community which they visited to give feedback about teachers' marking. This non-hierarchical interpretation of the Teacher Learning Community chimes with Lave and Wenger's (1991) concept of legitimate peripheral participation, in the sense that newcomers to the 'guild' of teachers had a legitimate place in the discussions. Where Lave and Wenger's model differs, however, is in its view that old-timers know the 'best practice', while Wiliam's model of Teacher Learning Communities suggests that best practice is constructed by participants according to contextual particulars.

The accountability in these Communities was to the group, not to the authorities, as one teacher in Westend School commented. For this reason, care was taken in appointing a leader for any Community. The lead teacher in Hillside School decided it was not appropriate for any member of SMT to lead the Teacher Learning Community as they would 
be too directive which would decrease collaboration. In some Communities, one (non-SMT) person volunteered to lead all sessions which allowed them to get very involved in the project; while in others someone different took the lead each time, and thereby a spread of leadership skills was developed among non-SMT teachers. Sometimes, the leader was appointed by the SMT. One teacher claimed that the most important factor was how the leader addressed the group, rather than who s/he was. It was more useful if the leader used the language in the of 'needing' to carry out actions rather than 'having' to: this language suggested that the aim of the Teacher Learning Community was developing practice rather than carrying out instructions.

Yet again, the messages that come through the teachers' comments from this research about collaborative dialogue apply to AfL classrooms as well as to Teacher Learning Communities. In a classroom where everyone's voice is heard and valued and where pupils and staff support each other, critical, divergent negotiations of meanings and solutions are more likely than in a class which is directly controlled by a leader who imposes an agenda. The success of AfL strategies which embody the spirit as well as the letter of AfL, like successful Teacher Learning Communities, draws on a collaborative culture where everyone's voice in the negotiations is respected and valued.

\section{Information is given from within and beyond the school to support teachers' theoretical as} well as practical learning

Studies suggest that collaboration may be a necessary but not sufficient element of useful CPD. Hawley and Valli (1999) suggest that in addition to collaboration in Teacher Learning Communities, teachers need access to input from within and beyond the school to support 
their theoretical as well as practical learning. Consultant CM suggested that this aspect of tended to be overlooked:

There's the potentially very powerful professional development model of the Teacher Learning Community, with its potential to take existing knowledge, draw in the knowledge of academics, academic theory and research, and then create new knowledge. Now, I don't think a lot of the Teacher Learning Communities have grasped that as a deep point...There was... a reluctance to engage with what are perceived as theoretical constructs, theoretical material. [Teachers say:] "What do they [academics] know about teaching? They should have been in my lesson this afternoon."

The lead teachers in Hillside School and Pleasant Row School both agreed that, although meetings might also make teachers think more deeply, teachers were often mainly interested in strategies: 'They just want new things that are original constantly coming at them' [Hillside School]. One simple way of extending input beyond 'technique swopping' was by making it a requirement to discuss at departmental level what was happening in Teacher Learning Communities [Hillside and Southview]. The lead teacher at Southview School also described the energy and excitement teachers in her school felt when they found new external materials for themselves, which they wanted to share with the rest of the Community on their school intranet. In these schools, therefore, the need for some external input was clearly acknowledged as helpful to learning.

All Teacher Learning Communities used the external materials provided by Wiliam at the initial training days. Each month's agenda in these packs included some new input about an AfL practice, which aimed to provoke the teachers to reflect on the purposes and principles 
behind each practice. The lead teacher at Pleasant Row School felt that '... having a high quality pack that we can use as a starting point is excellent'. Teachers could constantly derive new input from these extensive materials, if they chose to or their leader encouraged it. However, some teachers in Pleasant Row School found the materials from the initial training days actually 'a little overbearing'. Rather than seeing them as potential for exciting new learning, they perhaps anticipated that they would be prescriptive, irrelevant and burdensome. These teachers may have recognised the need for new input, but wanted exciting and varied new input that was easy to manage.

In Westend School, teachers attended a presentation by a Teacher Learning Community in another school and said they gained insights from this. A teacher in the same school told me that Dylan Wiliam's own presentation at the start of the project was the high point of the project for her. Others, however, mentioned that the presentation did not address practicalities enough [Southview School] and consultant CA was also negative:

For many, the connection of the power of AfL, in terms of driving learning, had completely escaped them. Despite - you know, it's the classic one - despite having been exposed to some fairly forceful presentations by Dylan, it had not taken root.

As in school classrooms, so in Teacher Learning Communities, when exciting links are made with research and practice outside the individual learning site, then divergent possibilities open up. It seems clear that if the site of learning is perceived as the limit of the learning, then limited learning is the likely outcome. The provision of research findings from research bodies outside the school provides learners - whether pupils or teachers - with some useful evidence for arguing an important teaching or learning point from a position of knowledge and therefore strength. 


\section{Implications for those involved in teachers' professional development in schools}

The aim of this paper has been to consider the features of CPD most closely related to a productive outcome, as indicated by the research literature, and to explore teachers' experiences of each feature in terms of their learning in the Teacher Learning Communities they attended. Now some implications are drawn out. Those involved in teachers' professional development in schools would do well to note that teachers in this study were clear about Teacher Learning Communities being more productive when leaders respected and valued each teacher's own particular needs, which were identified as of importance to the teacher as an individual professional. Teachers in the one voluntary Community evidenced confidence, enthusiasm and commitment beyond that seen in the compulsory ones. While a few teachers did believe that some coercion was helpful, teachers in those Teacher Learning Communities which were flexible and responsive to their participants' needs tended to report most satisfaction with the process. The indication from this research therefore seems to be that our schools are ready for a paradigm shift in terms of their own agenda: the English government's involvement in the fabric of teachers' own classroom practice has had the downward spiralling effect of teachers not expecting to take responsibility for their own development. It is worth reflecting on the fact that in Finland, where education is much lauded, teachers choose their own focus for professional development and the state funds their choice (Sahlberg, 2010).

Some teachers saw the benefits of the ongoing nature of the Teacher Learning Communities, in contrast to 'one-off' sessions. Although three out of four schools' meetings were compulsory, having the Teacher Learning Communities on the school calendar and counting them as part of the government imposed INSET days, helped to keep them going. 
Teachers in those Communities where collegial observations happened voluntarily and frequently seemed to find these very helpful, while teachers where these observations where either prescribed or did not happen, found the observations at best unhelpful and at worst destructive. As the teacher quoted above reminded us, being observed is a very sensitive experience and a conducive culture may need to be established voluntarily among peers before any requirements can be made.

Perhaps the feature of Teacher Learning Communities that is most important to note was collaboration. Even if teachers were only there to learn a new technique or earn an extra day's holiday, most seemed to appreciate the chance to work together with colleagues and talk about their practice. Collaboration was enhanced specifically by the accountability built into the Teacher Learning Community model: teachers made commitments to their colleagues to try something out, and then to return later and tell them what happened. When this occurred among colleagues who felt comfortable with each other, where no fear was present, this could be a spectacularly powerful process. However, issues of leadership and group constitution were not easily resolved, and schools were trying out different arrangements to see what worked best. In one school, an egalitarian ethos was explicit and newly qualified teachers seen as inspirational [Southview]. In others, perhaps where SMT appointed the leaders, teachers seemed less free to express themselves reflecting their school's particular fear of OFSTED surveillance.

In relation to teachers using information outside meetings either from within or beyond the school to support their theoretical as well as practical learning, for some Teacher Learning Communities this stopped at the use of Wiliam's agenda. Some teachers actually objected to Wiliam's externally provided materials as too burdensome. Others, however, saw them as a useful starting point for learning. The training at the start of the process was clearly 
inspirational but seemingly not in a sustained way for all the teachers interviewed. This was perhaps the aspect of successful CPD that these teachers focused on least and therefore deserves particular reflection here. It appeared that much of the original materials pack was not used during meetings. For example, video clips of Wiliam talking and his exemplars of strategies might have helped address the lack of alternative external inputs, but were not used. Another way forward for these Teacher Learning Communities might have been to do as teachers did in a similar project in Hong Kong (see Hargreaves, Berry, Leung, Scott and Stobart, 2012 under review) whereby groups of schools met together every eight weeks for inter-school, subject specific Teacher Learning Communities in addition to their schoolbased, cross-curricular ones.

Success in this study was not measured numerically in terms of pupil attainment. This study was too small to allow such an analysis. As with AfL effectiveness more generally, more expansive research is clearly called for including quantitative measures which correlate teachers' Teacher Learning Community involvement to student attainment (Bennet, 2009; Dunn \& Mulvenon, 2011). However, measuring cause and effect in the case of Teacher Learning Communities can be problematic even when large numbers are included (Louis and Marks, 1998). For example, our findings in our much larger Hong Kong study found no direct correlations between Teacher Learning Communities and student attainment, and yet a wealth of benefits were reported by the teachers involved (Hargreaves et al, 2012 under review). The usefulness of the Teacher Learning Communities is evaluated in the current study only through the subjective perspectives of the teachers involved and by comparing these to the research about useful CPD. The study focused on teachers claiming to develop confidence, belief in their power to make a difference, enthusiasm for collaborative working and commitment to changing practice. In these senses, the teachers in this study found the 
process useful as CPD, more or less to the extent that they met the criteria listed for successful CPD.

However, teachers also made some qualitative comments about the good effects of the Teacher Learning Community process on their students' learning. As an illustration, these included comments to the effect that teachers were moving into the role of facilitators rather than the ones who are in control of everything. At the minimal level, teachers considered that through AfL, their students were becoming 'independent' or less needy of 'spoon-feeding'. One lead teacher talked about now 'giving ownership of progression to students' [Hillview School], encouraging students to take responsibility for their own progression. Ownership might still be at a relatively superficial level, but there was evidence for an invigorated teacher goal of sharing expertise among learners. For example, it might start with inviting learners to respond to feedback comments rather than reacting to grades. In one school, as a result of the Teacher Learning Community process, teachers had started to show students how to give each other feedback and thus peer and selfassessment became more developed. Some teachers stressed that increased engagement and confidence accompanied students' increased independence. At one level, the 'no hands-up' AfL strategy of picking randomly on students was seen to keep students on their toes and in the best cases, increase their confidence to speak. At a further level, students might actually play a role in critiquing teaching in the classroom and its impact on learning. For example, in Hillview School students were invited to feed back to the Teacher Learning Community about how useful they found teacher marking: and then their recommendations were actually acted on. 
In conclusion, it is apparent from this study that the Teacher Learning Communities are a process of teacher development that has the potential to work productively in schools because their design allows them to be responsive to needs, to be ongoing, collaborative and inspired by external input too. However, schools have their own specific ways of functioning and their own agenda that they seek to achieve through establishing Communities. It is important to notice that where implementation of the Teacher Learning Community design is compromised by a need to meet one size fits all policy directives, and where educational research into useful CPD is not heeded, the outcomes of the Communities may be limited. Therefore, like AfL in the classroom, so in the Teacher Learning Community, both teachers and learners need continually to be '... questioning the potential advantages and disadvantages of different methods' and the promise of these methods for enhancing valuable learning (Lefstein, 2005, p.350). As the lead teacher in Hillside School commented, neither CPD nor AfL is a 'magic wand' or a 'magic switch', neither is an 'overnight thing', and both rely for their success on sustained critical reflection among their participants. In a political climate where critical reflection on established traditions and on policy directives is not encouraged, both implementing AfL critically and engaging in Teacher Learning Communities critically might mean teachers 'working against the grain' (Watkins et al, 2005). The research presented here suggests that taking this risk has led to increased learning and well-being in some London schools.

\section{References}

Alexander, R. (Ed.). (2010). Children, their world, their education. Oxford: Routledge. 
Baker, S. \& Smith, S. (1999). Starting off on the right foot: The influence of four principles of professional development in improving literacy instruction in two kindergarten programs. Learning Disabilities Research and Practice, 14 (4), 239-53. DOI: 10./1207/sldrp1404_5

Bassey, M. (2001). A Solution to the problem of generalisation in educational research: fuzzy Prediction. Oxford Review of Education, 27 (1), 5 - 22.

Beck, J. (2008). Governmental professionalism: re-professionalising or de-professionalising teachers in England? British Journal of Educational Studies, 56 (2), 119-143. ISSN 0007-1005

DOI number: 10.1111/j.1467-8527.2008.00401.

Bennet, R. (2009). A critical look at the meaning and basis of formative assessment. New Jersey: ETS.

Black, P.J. (1994). Assessment and accountability: the experience in England and Wales. Educational Evaluation and Policy Analysis, 16 (2), 191-203. DOI:

$10.3102 / 01623737016002191$

Black, P. \& Wiliam, D. (1998). Inside the Black Box. London: King's College.

Cassidy, C., Christie, D., Coutts, N., Dunn, J., Sinclair, C., Skinner, D., \& Wilson, A. (2008).

Building communities of educational enquiry. Oxford Review of Education, 32 (2), 217-235.

DOI: $10.1080 / 03054980701614945$

Dunn, K. \& Mulvenon, S. (2011). A critical review of research on formative assessment: the limited scientific evidence of the impact of formative assessment in education. Arkansas: University of Arkansas.

DSCF, (2008). AfL Strategy [online]. DSCF. Retrieved from www.teachernet.gov.uk/publications 
DFE, (2011). Effective Primary Pedagogical Strategies in English and Mathematics in Key

Stage 2: A study of Year 5 classroom practice drawn from the EPSE 3-16 longitudinal study. London: DFE.

Earley, P. \& Porritt, V. (2010). Effective practices in continuing professional development: lessons from schools. London: Institute of Education.

Ecclestone, K. (2010). Instrumentalism and achievement: a socio-cultural understanding of tensions in vocational education. London: Sage.

Gipps, C. (1994). Beyond testing. London: RoutledgeFalmer.

Hargreaves, E., (2005). Assessment for learning? Thinking outside the (black) box. Cambridge Journal of Education, 35 (2), 213-224. DOI: 10.1080/03057640500146880

Hawley, W. \& Valli, L. (1999). The essentials of professional development: A new consensus. In L. Darling-Hammond and G. Sykes (Eds.), Teaching as the learning profession: Handbook of policy and practice (151-180). San Francisco: Jossey-Bass.

Hustler, D., McNamara, O., Jarvis, J., Londra, M. \& Campbell, A. (2003). Teachers' Perceptions of CPD. Research Report RR429. London: Department for Education and Skills. Jackson, C. (2010). Fear in education. Educational Review, 62 (1), 39 - 52. DOI: $10.1080 / 00131910903469544$

Lave, J., \& Wenger, E. (1991). Situated learning. Legitimate peripheral participation. Cambridge: University of Cambridge Press.

Leahy, S., \& Wiliam, D. (2012, forthcoming). From teachers to schools: scaling up professional development for formative assessment. In J. Gardner (Ed.), Assessment and learning (2nd edition). Thousand Oaks, CA: Sage. 
Lefstein, A. (2005). Thinking about the technical and the personal in teaching. Cambridge Journal of Education, 35, (3), 333-356. DOI: 10.1080/03057640500319040

Little, J.W., (1992). The black box of professional community. In A. Lieberman (Ed.), The changing contexts of teaching (157-178) Chicago: University of Chicago Press.

Lom, E. \& Sullenger, K. (2011). Informal spaces in collaborations: exploring the edges/boundaries of professional development. Professional Development in Education, 37 (1), 55-74. DOI: 10.1080/19415257.2010.489811

Louis, Karen S. \& Marks, Helen M. (1998). Does professional community affect the classroom? Teachers' work and student experience in restructuring schools. American Journal of Education, 106 (4), 532-575.

Marshall, B. \& Drummond, M. (2006). How teachers engage with AfL: lessons from the classroom. Research Papers in Education, 21 (2), 133-149. DOI: 10.1086/444197

McKenzie, P. \&, P. (2005). Teachers Matter: Attracting, Developing and Retaining Effective Teachers. Paris: OECD Publishing.

Mushayikwa, E. \& Lubben, F. (2009). Self-directed professional development - hope for teachers working in deprived environments. Teaching and Teacher Education, 25, 375-382. DOI: $\underline{10.1016 / \text { j.tate.2008.12.003 }}$

Pedder, D., James, M. \& MacBeath, J. (2005). How teachers value and practise professional learning. Research Papers in Education, 20, (3), 209-243. DOI:

http://dx.doi.org/10.1080/02671520500192985

Pryor, J. \& Crossouard, B. (2008). A sociocultural theorization of formative assessment. Oxford Review of Education, 34 (1), 1-20. DOI: 10.1080/03054980701476386 
Ryan, R. \& Deci, E. (2000). Self-determination theory and the facilitation of intrinsic motivation, social development and well-being. American Psychologist, 55 (1), 68-78. DOI:

\section{$\underline{10.1037 / 0003-066 X .55 .1 .68}$}

Sahlberg, J. (2010). Rethinking accountability in a knowledge society. Journal of Educational Change 11, 45-61. DOI 10.1007/s10833-008-9098-2

Schechter, C. (2010). Learning from success as leverage for a professional learning community: exploring an alternative perspective of school improvement process. Teachers College Record, 112, 1, 182-224.

Schwille, J. \& Dembele, M. (2007). Global perspectives on teacher learning: improving policy and practice. Paris: UNESCO, International Institute for Educational Planning.

Stoll, L., Bolam, R., McMahon, A., Wallace, M., \& Thomas, S. (2006). Professional learning communities: a review of the literature. Journal of Educational Change, 7, 221-258. DOI: 10.1007/s10833-006-0001-8

Stobart, G. (2008). The uses and abuses of assessment. London: RoutledgeFalmer. Thompson, M. \& Wiliam, D. (2008). Tight but loose: a conceptual framework for scaling up school reforms. In E. C. Wylie (Ed.), Tight but loose: scaling up teacher professional development in diverse contexts (1-44). NJ: ETS.

Torrance, H. and Pryor, J. (1998). Investigating formative assessment. Buckingham: OUP. Van Damme, D. (2009). OECD/CERI Research on innovating teaching and learning. Paris: OECD. 
Villegas-Reimer, E. (2003). Teacher professional development: An international review of the literature [online]. UNESCO. Retrieved from http://www.unesco.org/iiep [Accessed $27^{\text {th }}$ November 2011].

Watkins, C. (2001). Learning about learning enhances performance. London: NSIN.

Watkins, C. (2005). Classrooms as learning communities: what's in it for schools? London: Routledge.

Wiliam, D. (2008) Developing classroom practice: Meeting regularly in teacher learning communities is one of the best ways for teachers to develop their skill in using formative assessment. Educational Leadership, 65 (4), 36-42. 